\title{
Farkedilmeyen angulus mandibula fraktürü: sıradışı bir derin boyun enfeksiyonu nedeni
}

\author{
Unrecognized mandibular angular fracture : an extraordinary cause of deep neck infection
}

\author{
Sinan Atmaca ${ }^{a^{*}}$, Tahir Tulga ${ }^{a}, E^{2}$ rah Gönülol ${ }^{b}$, Senem Çengel Kurnaz ${ }^{a}$ \\ ${ }^{a}$ Ondokuz Mayıs Üniversitesi Tıp Fakültesi, Kulak Burun Boğaz Anabilim Dalı, Samsun \\ ${ }^{b}$ Ondokuz Mayıs Üniversitesi Diş Hekimliği Fakültesi, Ağız Diş ve Çene Hastalıklarl Cerrahisi Anabilim Dalı, Samsun
}

\begin{tabular}{|c|c|}
\hline \multicolumn{2}{|c|}{ MAKALE BİLGILERİ } \\
\hline Makal & \\
\hline Geliş & $22 / 12 / 2010$ \\
\hline Kabul & $23 / 12 / 2010$ \\
\hline
\end{tabular}

\section{* Yazıșma Adresi:}

Sinan Atmaca

Ondokuz Mayıs Üniversitesi

Tip Fakültesi

Kulak Burun Boğaz Anabilim Dalı,

Kurupelit 55139 Samsun

E-posta: sinanatmaca@yahoo.com

\section{Anahtar Kelimeler: \\ Derin boyun enfeksiyonu \\ Mandibula fraktürü \\ Bilgisayarlı tomografi \\ Panoramik mandibula grafisi \\ Apse \\ Diş kökenli}

\section{Keywords:}

Deep neck infection

Mandibular fracture

Computerized tomography

Panoramic mandible graphy

Abscess

Dental origin

\section{ÖZET}

Derin boyun enfeksiyonları, yüksek mortalite ve morbiditeleri nedeniyle hızlı teşhis ve tedavi edilmesi gereken önemli bir hastalık grubudur. Bu nedenle etiyoloji ve tanıya yönelik radyolojik değerlendirme önem kazanmakta ve tedavi de buna göre planlanmaktadır. Bu makalede, 44 yaşında derin boyun enfeksiyonu olan bir olgu sunuldu. Hastanın 15 günlük öyküsü vardı ve bu süre boyunca dış merkezde odontojenik enfeksiyon tanısıyla oral antibiyotik tedavisi görmüştü. Hasta yatırılarak IV antibiyotik başlandı. Kontrastlı bilgisayarlı tomografide, abseyle uyumlu bulgular dışında başka bir patoloji saptanmadı ve ponksiyonla pürülan sıvı boşaltıldı. Ancak çekilen panoramik mandibula grafisinde, bilgisayarlı tomografinin saptayamadığ tandı. Bunun üzerine tedavinin 11. gününde diş çekimi ve mandibulaya mini plak-vida ile internal fiksasyon yapıldı. Mandibula fraktürlerinde, bilgisayarlı tomografinin yanında mutlaka panoramik mandibula grafisi de çekilmelidir. J. Exp. Clin. Med., 2011; 28:195-197

\begin{abstract}
Deep neck infections should be instantly diagnosed and treated because of high morbidity and mortality rates. Radiologic imaging plays an important role in determining etiology and diagnosis and the treatment is planned accordingly. We present a 44-year old female patient with a 15 day history of oral antibiotic treatment for dental infection before admission. The patient was hospitalized and put on IV antibiotics. Computerized tomography with contrast revealed findings consistent with an abscess and pus was drained surgically. Panoramic mandible graphy revealed a non-displaced mandibular angular fracture unrecognized by the computerized tomography. The patient underwent tooth removal and internal fixation of the fracture with mini plate and screws. Besides computerized tomography, panoramic mandible graphy is a must for evaluation of mandibular fractures.

J. Exp. Clin. Med., 2011; 28:195-197
\end{abstract}

(C) 2011 OMÜ Tüm hakları saklıdır

\section{Giriş}

Derin Boyun Enfeksiyonu (DBE), boyundaki potansiyel boşluklarda enfeksiyon gelişmesiyle oluşur. Geçmişte, DBE'ler yüksek mortalite ve morbiditeye neden olmaktayd. Görüntüleme yöntemlerinde ve özellikle antibiyotiklerde sağlanan gelişmeler sayesinde bugün artık DBE'lerin tedavisinde belirgin klinik başarı sağlanmaktadır. Ancak halen yaygın görülen ve mortalitesi nedeniyle dikkatli bir klinik değerlendirme ve tedavi süreci gerektiren bir durumdur. Yetişkinlerde en sık neden, kötü dental hijyenken, çocuklarda tonsillitlerdir (Parhiscar ve Har-El, 2001; Agarwal et al., 2007; Marioni et al., 2008). Ayrıca mandibula fraktürü, IV uyuşturucu kullanı- mı ve nadir de olsa yabancı cisimler DBE'nin önemli sebepleri arasında yeralmaktayken, hastaların \%22'sinde etiyoloji saptanamamaktadır (Parhiscar ve Har-El, 2001; Yasar et al., 2005; Chung et al.,2008). Bakteriyolojik incelemede s1klıkla etken polimikrobiyalken, en sik izole edilen etken Streptococcus viridans'tır (Parhiscar ve Har-El, 2001). Düşük sosyoekonomik düzeyde daha sık görülmektedir (Agarwal et al., 2007). DBE'de tedavi planlanırken; hastanın demografik verileri, enfeksiyonun yerleşim yeri, etiyolojisi, kronik sistemik hastalıkların varlığ 1 değerlendirildikten sonra radyolojik değerlendirme yapılmalıdır. Radyolojik değerlendirmede halen altın standart, kontrastlı bilgisayarlı tomografidir (BT) (Su- 
ehara et al., 2008). Geniş vaka serili çalışmalarda kontrastlı BT ile cerrahi bulgular arasında \%68-83 oranında korelasyon olduğu saptanmıştır (Marioni et al., 2008). Ayrıca, odontojenik kökenli DBE'de panoramik mandibula grafisi etiyolojiyi ortaya koymakta çok değerlidir (Marioni et al., 2008).

\section{Olgu}

Kırk dört yaşında kadın hasta kliniğimize boyunda şişlik şikayetiyle başvurdu. Hastanın boyun sağ tarafta yaklaşık 15 gündür olan, son 2 günde hızla büyüyen şişlik vardı. Bu 15 günlük süreçte bu şikayetle dış merkezde bir diş hekimine başvurmuştu ve hastaya sorunun diş kökenli bir enfeksiyon olduğu anlatılıp oral antibiyotikler başlanmıştı. Ancak şikayetinin giderek daha da rahatsız edici hal alması üzerine başvurduğu KBB hekimince hasta bölümümüze yönlendirilmiş. Hastanın öyküsünde ateş ve ağrı yakınmaları da vardı. Hastanın dental girişim öyküsü yoktu. Travma sorguland1ğında hastanın yaklaşık 15 gün önce beton zeminde düştüğü öğrenildi, ancak hasta travmanın önemsiz olduğunu yalnızca kolunda ağrı olduğunu belirtiyordu. Hastanın muayenesinde; sağda mandibula korpusu boyunca devam eden, arkada submastoid bölgeye uzanan, aşağıda hyoid kemik hizasına, yukarıda bukkal bölgeye kadar uzanan, üzeri hiperemik ciltle kapl1, sert kıvamlı ancak korpus mandibula üzerinde bir noktada fluktuasyonun alındığ 1 dolgunluk mevcuttu. Yine oral kavite muayenesinde ağız tabanının dolgun olduğu, bu dolgunluğun vestibulumda, gingivobukkal sulkus boyunca retromolar trigona kadar uzandığı görüldü. Hastanın ağız açıklığı kısıtlıydı ve ağızda kötü bir koku olduğu gözlendi. Hasta yatırılarak IV Ampisilin-Sulbaktam tedavisi başlandı ve kontrastlı BT çekildi. BT'de sağ submandibuler bölgeden başlayıp palatin tonsil ve yumuşak damağa uzanan, aşağıda ağız tabanı düzeyine kadar gelen angulus mandibula düzeyinde öne doğru dönerek mandibula lateral kesiminde masseter kasina kadar devam eden ince kontrastlanan düzensiz bir duvarı bulunan, santrali hipodens, içerisinde yer yer kontrastlanan septalar izlenen, boyutları $4 \times 4 \times 3,5 \mathrm{~cm}$ olan abse ile uyumlu yumuşak doku lezyonu izlendi (Şek. 1 ve 2).

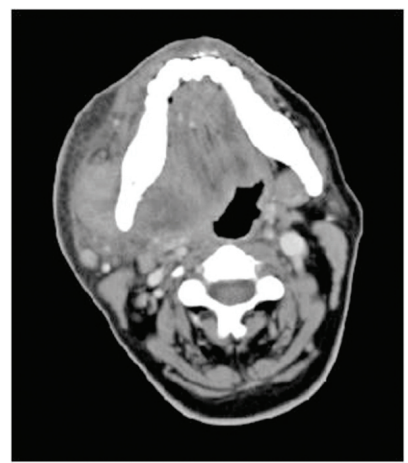

Şek. 1. Sağ tarafta,(mandibula) derin boyun enfeksiyonu ve abse ile uyumlu kontrastlı BT görüntüsü

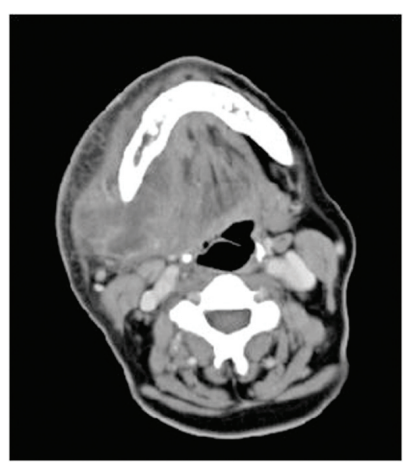

Şek. 2. Sağda mandibula angulus unun sağlam izlendiği kontrastlı BT görüntüsü
Ayrıca sağ bukkal bölgede ve boyun sağ anterior kesiminde orofarenks düzeyinden larinks düzeyine kadar submental bölgeye de uzanan alanda ciltaltı yağ dokusunda heterojenite gözlendi. Tedavinin 2. gününde mandibula korpusu alt hizasından ponksiyon yapıldı yaklaşık $20 \mathrm{cc}$ pürülan drenaj oldu. $\mathrm{Bu}$ materyalin kültüründe üreme saptanmadı. Tedavinin 5 . gününde dental değerlendirme sonrasında çekilen panoramik mandibula grafisinde angulus mandibulada düzgün sınırlı, 8 . sağ alt molar diş kökünü de içine alan nondeplase kırığın olduğu görüldü (Şek. 3).

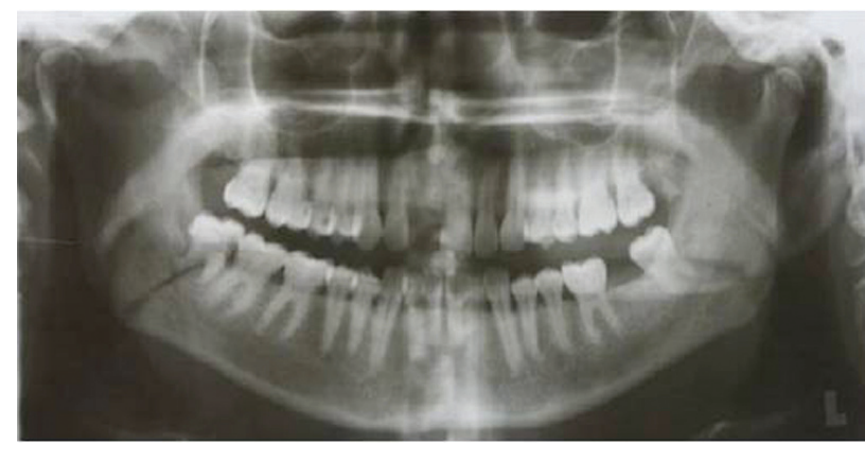

Şek. 3. Cerrahi drenaj sonrası panoramik mandibula grafisinde sağda, 8. alt molar diş kökünü içine alan non-deplase angulus mandibula kırığ 1

Bunun üzerine hastanın tedavisi tekrar planlandı ve mini plak-vida ile açı redüksiyon-internal fiksasyon (ARİ) yap1lmasına karar verildi. Tedavinin 10. gününde kliniğin oldukça gerilediği ve ağız açıklığının düzeldiği gözlendi. Bunun üzerine tedavinin 11. gününde, lokal anestezi altında diş çekimi ve mini plak-vida ile ARİF yapıldı (Şek. 4).

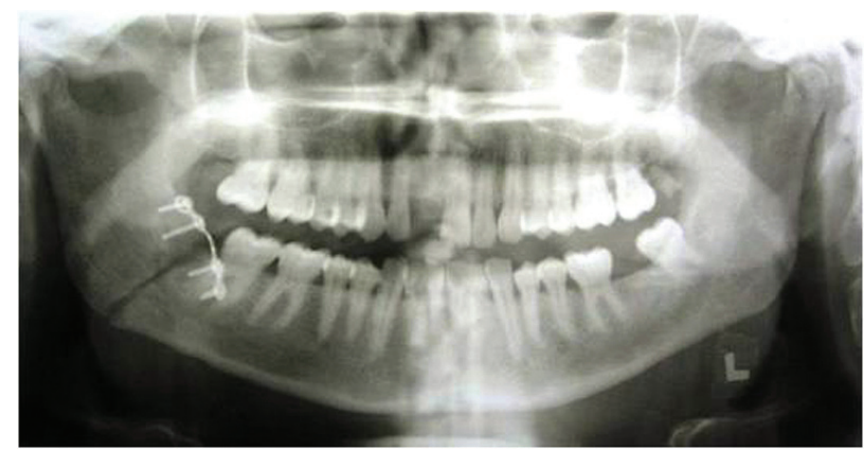

Şek. 4. Diş çekimi ve internal fiksasyon sonrası panoramik mandibula grafisi

Hastanın IV antibiyotik tedavisi 14 güne tamamlanarak oral Amoksisilin-Klavulanat tedavisiyle taburcu edildi. Birinci hafta kontrolünde submandibuler bölgede minimal dolgunluk mevcuttu . İkinci hafta kontrolünde muayenede herhangi bir patolojiye rastlanmadi.

\section{Tartışma}

DBE'ler, yüksek mortalite ve morbiditeye neden olabilen klinik tablolardır. Kliniğimizde sık karşılaştığımız, ancak etkin parenteral antibiyotik tedavisi ve cerrahi drenajla tatminkar sonuçlar elde ettiğimiz bir durumdur. Etiyolojide yetişkinlerde ilk sırayı odontojenik nedenler alırken, çocuklarda tonsillitler almaktadır (Parhiscar ve Har-El, 2001; Agarwal et al., 2007; Marioni et al., 2008). Tanıda, tercih edilen radyolojik yöntemler; direkt grafiler (lateral servikal grafi, PA akciğer grafisi, panoramik mandibula grafisi), bilgisayarlı tomografi, manyetik rezonans görüntüleme ve ultrasonografidir (Parhiscar ve Har-El, 2001; Marioni et al., 2008; Suehara et al.,2008). Kliniğimizde sıklıkla anatomik ilişkilerin, kemik yapının ve hava pasajının değerlendirilmesinde etkinliği nedeniyle BT'yi tercih etmekteyiz. Kontrastsız BT'nin duyarlılığı \%95 iken, bu oran kontrastlı BT'de, \%100'e çıkmaktadır. Panoramik mandibula grafisi de, bu olgularda dental etiyolojiyi sap- 
tamak için çekilmektedir. Bu olguda, panoramik mandibula grafisi, BT'nin gösteremediği angulus mandibula fraktürünü ortaya koydu. Bu gelişme sonrasında, hastanın BT'leri bölümümüz ve radyoloji bölümünce tekrar değerlendirildi, ancak yine BT'de fraktür hattı gözlenmedi. Bu olguda; kontrastlı BT, yüksek sensitivitesine rağmen kırığı saptamada yetersiz kalmıştır, ancak çekilen panoramik mandibula grafisiyle kırık saptanabilmiştir. Kontrastlı BT, absenin lokalizasyonunun ve niteliğinin değerlendirilmesinde oldukça kıymetli ve duyarlıdır bir yöntemdir ancak burada kemik dokuyu değerlendirmede yetersiz kalmıştır. Maksillofasiyal travma sonrasında, mandibulada fraktür şüphesi olan hastalarda BT'ye ek olarak mutlaka panoramik mandibula grafisi de çekilmelidir.

\section{KAYNAKLAR}

Agawal, A.K., Sethi, A., Mrig, S., Chopra, S., 2007. Role of socioeconomic factors in deep neck abscess: A prospective study of 120 patients. Br. J. Oral Maxillofac. Surg. 45, 553-555.

Chung, S.M., Kim, H.S., Park EH., 2008. Migrating pharyngeal foreign bodies: A series of four cases of saw-toothed fish bones. Eur. Arch. Otorhinolaryngol. 265, 1125-1129.

Marioni, G., Rinaldi, R., Staffieri, C., Marchese-Ragona, R., Saia, G., Stramare, R., Bertolin, A., Dal, Borgo, R., Ragno, F., Staffieri, A., 2008. Deep neck infection with dental origin: Analysis of 85 consecutive cases (2000-2006). Acta Otolaryngol. 128, 201-206.

Parhiscar, A., Har-El, G., 2001. Deep neck abscess: A retrospective review of 210 cases. Ann. Otol. Rhinol. Laryngol. 110, 1051-1054.

Suehara, A.B., Gonçalves, A.J., Alcadipani, F.A., Kavabata, N.K., Menezes, M.B., 2008. Deep neck infection: Analysis of 80 cases. Rev. Bras. Otorrinolaringol. 74, 253-259

Yasan, H., Doğru, H., Özel, B.F., Baykal, B., 2005. Difficulty in the diagnosis and management of parapharyngeal abscess: Foreign body. KBBForum. 4, 192-194. 